\title{
Morbidly adherent placenta and it's maternal and fetal outcome
}

\author{
Ranjana Desai, Bhanwar Singh Jodha, Richa Garg*
}

Department of Obstetrics and Gynecology, Umaid Hospital, Jodhpur, Rajasthan, India

Received: 17 February 2017

Accepted: 24 March 2017

*Correspondence:

Dr. Richa Garg,

E-mail: richagarg1989@gmail.com

Copyright: (c) the author(s), publisher and licensee Medip Academy. This is an open-access article distributed under the terms of the Creative Commons Attribution Non-Commercial License, which permits unrestricted non-commercial use, distribution, and reproduction in any medium, provided the original work is properly cited.

\begin{abstract}
Background: Morbidly adherent placenta, a grave complication of pregnancy is becoming an emerging cause of increased maternal morbidity and mortality. Objectives of present study are to evaluate the etiopathogenesis of MAP, its clinical mode of presentation and maternal and fetal outcome with the aim to reduce maternal morbidity and mortality.

Methods: It was a retrospective and prospective study at Umaid Hospital, attached to Dr. S.N. Medical College, Jodhpur in which data of patients with clinical diagnosis of MAP were reviewed from October 2014 to January 2016.

Results: In this study of 10 cases of morbidly adherent placenta of Umaid hospital from October-2014 to January 2016 were studied, it was found that the mean age of presentation was 30.2 year. $60 \%$ cases were unbooked and $40 \%$ cases were booked with regular ANC visit. $60 \%$ cases presented with bleeding per vagina as a chief complaint and $30 \%$ cases were admitted for elective LSCS. $60 \%$ cases were already diagnosed case of placenta praevia. $90 \%$ cases had a history of previous LSCS. $80 \%$ cases were given BT intraoperatively and postoperatively. $60 \%$ cases underwent caesarean hysterectomy, $80 \%$ cases were shifted to ICU, and there was one maternal death.

Conclusions: The incidence of MAP is increasing due to higher cesarean section $(\mathrm{C} / \mathrm{S})$ rate. Antenatal diagnosis via USG and color-doppler imaging, preoperative counseling, planning and multidisciplinary approach is necessary to reduce morbidity and mortality associated with MAP.
\end{abstract}

Keywords: Caesarean hysterectomy, Increta, Percreta, Placenta accreta

\section{INTRODUCTION}

MAP is an abnormal invasion of placental tissue (trophoblast) into outer or inner myometrium or through the serosa of the uterus (termed as accreta, increta, percreta respectively). It is a potentially life threatening condition responsible for $7-10 \%$ of maternal mortality. ${ }^{1}$ Morbidly adherent placenta occur when there is partial or total absence of decidua basalis and Nitabuch layer.

The incidence of placenta accreta was approximately 1 in 4027 in 1970 s, 1 in 2510 in the 1980 s, 1 in 533 pregnancies in1982- 2002 and 1 in 210 in $2006 .{ }^{2}$ Marked increased in incidence of MAP is due to increased rate of caesarean sections. The two most important risk factors are an associated previa, a prior cesarean delivery, and more likely a combination of the two. Others risk factors are previous uterine surgery, previous dilatation and curettage, previous history of MRP previous myomectomy, ashermann Syndrome (endometrial defects), submucous leio- myoma, advanced maternal age, multiparity etc). ${ }^{3}$

MAP is classified according to the degree of penetration of chorionic villi and by the area of placental involvement, into 3 types. ${ }^{4}$

- Accrete (75\%): the placenta is attached to the myometrium. Clinical consequences of placenta accreta are uterine perforation, massive hemorrhage at the time of placental separation, infection, hysterectomy and associated comorbidites as ureteral 
injury and fistula formation (5\%), mortality (7.4\%), postoperative infection (28\%), transfusion (90\%).

- Increta (17\%): the placenta extends into the myometrium

- Percreta (7\%): the placenta extends through the entire myometrium and uterine serosa Placenta percreta is a catastrophic event in which uterine rupture may occur as early as 9 and 14 wks. It can lead to the destruction of adjacent organs, most often the bladder, or surgical injury of pelvic structures due to loss of tissue planes. $75 \%$ cases of percreta are associated with placenta previa.

Diagnosis of MAP requires a higher degree of suspicion and medical imaging can be an effective diagnostic tool. For this Transvaginal sonography is now well established as the preferred method for the accurate localization of a low-lying placenta. TVS is safe for patients with placenta previa, even when there is vaginal bleeding. Accuracy rates for TVS are high (sensitivity $87.5 \%$, specificity $98.8 \%$, positive predictive value 93 ), establishing TVS as the gold standard for the diagnosis of placenta. 5,6 Proper Antenatal ultrasound can be used to establish the diagnosis and guide clinical management. Signs of accretion may be seen as early as in the first trimester and they should undergo follow-up imaging later in the second and third trimester with attention to the potential presence of placenta accrete. ${ }^{7}$ Second and third trimester gray-scale sonographic characteristics include loss of continuity of the uterine wall, multiple vascular lacunae (irregular vascular spaces) within placenta, giving Swiss cheese appearance adjacent to the placental implantation site, lack of a hypoechoic border (myometrial zone) between the placenta and the myometrium, bulging of the placental/myometrial site into the bladder, and increased vasculature evident on color Doppler sonography. ${ }^{8}$

\section{METHODS}

This retrospective and prospective study was done in Obst/Gynae Department of Umaid Hospital, Jodhpur, Rajasthan from October 2014 to January 2016. The medical records of all the 10 women who were diagnosed to have MAP were reviewed.

Demographic data including age, parity, gestational age and previous caesarean delivery or other uterine surgery, details of medical and obstetric history and information on the intraoperative and postoperative events were recorded. In particular, from the surgery report we obtained data on placental location, estimated blood loss, blood transfusion, presence of placenta accreta, procedures needed to control bleeding. Neonatal outcomes were reviewed for birth weights, nursery admission and perinatal mortality.

\section{RESULTS}

There were 31046 deliveries from October 2014 to January 2016; among these 10 women met the diagnostic criteria of MAP making an incidence of $0.032 \%(1 / 3104$ deliveries) over 16 months' study period.

Table 1: Antenatal profile of patients.

\begin{tabular}{|ll|}
\hline Antenatal profile & $\begin{array}{l}\text { No. of } \\
\text { Patient }\end{array}$ \\
\hline No. of patients with previous & $9(90 \%)$ \\
\hline Caesarean section & \\
\hline $\begin{array}{l}\text { No. of Patients with diagnosed MAP in } \\
\text { USG }\end{array}$ & $1(10 \%)$ \\
\hline No. of Patients with placenta praevia & $6(60 \%)$ \\
\hline
\end{tabular}

$90 \%$ women had history of previous caesarean sections, Placenta Praevia was associated with $60 \%$ women. $60 \%$ Of women with adherent placenta had accreta; $30 \%$ percreta and $10 \%$ had increta.

Table 2: Demographic characters.

\begin{tabular}{|ll|}
\hline Demographic characters & No. of Patient \\
\hline Mean age & 30.2 \\
\hline Mean parity & 2.7 \\
\hline Un-booked & $6(60 \%)$ \\
\hline Booked & $4(40 \%)$ \\
\hline Previous 1 C-S & $6(60 \%)$ \\
\hline Previous 2 C-S & $2(20 \%)$ \\
\hline Previous 3 C-S & $1(10 \%)$ \\
\hline
\end{tabular}

Table 3: Type of MAP.

\begin{tabular}{|ll|}
\hline Type of MAP & Percentage \\
\hline Accreta & 60 \\
\hline Percreta & 30 \\
\hline Increta & 10 \\
\hline
\end{tabular}

Due to massive blood loss $80 \%$ cases were given Blood transfusion i.e. 1-5 units of whole blood and 50\% were given i.e. 2-6 units of fresh frozen plasma (FFP). $60 \%$ women were shifted to ICU with an average stay of 3 days.

Table 4: Morbidity associated with MAP.

\begin{tabular}{|ll|}
\hline Morbidity & No. of Patient \\
\hline Characteristics no. \% hysterectomy & $6(60 \%)$ \\
\hline ICU transfer & $8(80 \%)$ \\
\hline $\begin{array}{l}\text { Prolong hospital stay } \\
\text { (> than 7 days) }\end{array}$ & $9(90 \%)$ \\
\hline Blood transfusion & $8(80 \%)$ \\
\hline FFP transfusion & $5(50 \%)$ \\
\hline Bladder repair & $1(10 \%)$ \\
\hline Internal iliac artery ligation & $1(10 \%)$ \\
\hline $\begin{array}{l}\text { Mortality } \\
\text { (shock) }\end{array}$ & $\begin{array}{l}1(10 \%)(\text { due to } \\
\text { irreversible } \\
\text { haemorrhagic) }\end{array}$ \\
\hline
\end{tabular}

6 out of 10 women i.e. $60 \%$ had to undergo caesarean hysterectomy. 
The main newborn complication was prematurity and the average gestational age in our study was 32.1 weeks. $50 \%$ of the newborns were preterm with an average birth weight low birth weight $<2500 \mathrm{gm}$, i.e. $2.1 \mathrm{~kg}$. The perinatal mortality was $10 \%$.

Table 5: Neonatal outcome.

\begin{tabular}{|ll|}
\hline Neonatal outcome & Percentage \\
\hline Average gestational age & 32.1 weeks \\
\hline Preterm newborn among live births & $5(50 \%)$ \\
\hline Average birth weight & $2.1 \mathrm{~kg}$ \\
\hline Baby shifted to nursery & $6(60 \%)$ \\
\hline Perinatal mortality & $1(10 \%)$ \\
\hline
\end{tabular}

The urinary bladder is not seen in Figure 1 as it was below the incision site. Placenta percreta was confirmed after histological diagnosis.

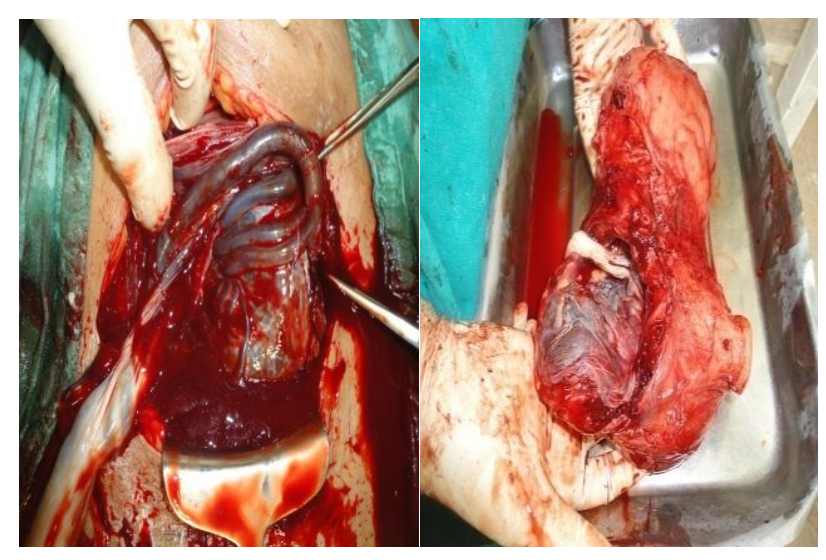

Figure 1: Numerous engorged and coherent vessels over the uterine serosa.

\section{DISCUSSION}

Keeping a probable diagnosis of MAP helps in saving maternal live. This helps in counseling and monitoring of high risk patients for MAP on the basis of history and USG. Both gray scale ultrasound and color Doppler examination are highly accurate in predicting the radiological patterns of placenta accreta. ${ }^{9}$

Clinical suspicion should be raised in all women with vaginal bleeding after 20 weeks of gestation. The definitive diagnosis of most low-lying placentas is now achieved with ultrasound imaging. The UK National Screening Committee supports practice of identifying at the routine 20 -week antenatal screening ultrasound scan of women whose placenta encroaches on the cervical os. and referral of those with previous caesarean, to tertiary centre will lead to timely diagnosis. ${ }^{10}$

Frequency of MAP in our study group was $1 / 3104$ i.e $0.032 \% .^{9}$ patients out of 10 patients i.e $90 \%$ were previous caesarean section ranging from 1 to 3 . It establishes that MAP is directly related with frequency of caesarean section. Every effort should be made to reduce percent of primary caesarean section so that morbidity and mortality related to MAP can be reduced. If cesarean rates continue to increase, the annual incidence of placenta previa, placenta accreta, and maternal death will also rise substantially. ${ }^{11}$

Women with major placenta praevia who have previously bled should be admitted and managed as in patients from 34 weeks of gestation and delivery by 36 week or earlier if bleeding occur at well-equipped tertiary centres with good NICU backup, blood bank facility, interventional radiologist at time of delivery. ${ }^{12}$

$60 \%$ women in our study group had to undergo caesarean hysterectomy, all were emergency hysterectomy however Seago et al demonstrated that planned cesarean hysterectomy in selected patients allows the surgical team to be prepared for complications to prevent morbidities with no demonstrable increase in intraoperative and postoperative complications, when compared with women who undergo hysterectomy within 6 months of cesarean delivery. ${ }^{13}$ Robinson et al BK too cites that there is a great benefit of planned as opposed to emergent peripartum hysterectomy. ${ }^{14}$ In mothers with placenta previa and a suspected accreta who required peripartum hysterectomy, a scheduled delivery has been associated with shorter operative times and lower frequency of transfusions, complications, and intensive care unit admissions .

The main newborn complication was prematurity and the average gestational age in our study was 32.1 weeks. 55 $\%$ of the newborns were preterm with an average birth weight low birth weight $<2500 \mathrm{gm}$, i.e. $2.1 \mathrm{~kg}$. The perinatal mortality was $10 \%$ So there are potential risk factors and outcomes of pregnancies in patients with incidence of placenta praevia.

The multidisciplinary team including a gynecologic surgeon experienced in pelvic surgery, a blood bank team prepared to administer multiple blood components along with a hematologist if difficulty with blood clotting develops, experienced anesthesiology personnel who are skilled in obstetric anesthesia, skilled urologists in case a bladder resection or repair might be required, experienced intensivists for postpartum care, and an experienced neonatologist in case a baby is very premature. In cases where pelvic artery catheterizations are used, an experienced interventional radiologist is also required. Additionally, Eller et al showed that delivery at a medical center with a multidisciplinary care team resulted in a more than $50 \%$ risk reduction for composite early morbidity among all cases of placenta accreta and a nearly $80 \%$ risk reduction. ${ }^{15}$

Due to massive blood loss in our study group $80 \%$ cases were given Blood transfusion i.e. 1-5 units of whole blood and 50\% were given i.e. 2-6 units of fresh frozen 
plasma (FFP). Mean estimated blood loss during surgery was 3 to 5 liters.

Maternal mortality in our study was $10 \%$, which is comparable to the rate of $7-10 \%$ as quoted in literature. ${ }^{16}$ The biggest risk with accretas is severe bleeding because the placenta cannot detach properly at birth. In the short term, this can require multiple blood transfusions, cause a life-threatening blood clotting crisis, or necessitate a hysterectomy. In the long term, it can cause postpartum anemia, difficulty breastfeeding, or even Sheehan's Syndrome (damage to the mother's pituitary gland, resulting in long-term health problems). Since major blood loss is the biggest risk of an accreta treatment of accretas usually revolves around trying to proactively prevent as much blood loss as possible. Correction of anaemia prior to expected blood loss. Blood bank preparations include arrangement of cross matched blood and component therapy. It will help to reduce maternal morbidity and mortality.

\section{CONCLUSION}

Early antenatal diagnosis of morbidly adherent placenta, proper counselling of patients regarding associated risks followed by well-planned caesarean hysterectomy with non-separation of placenta adopting multidisciplinary approach is the management option to reduce maternal morbidity and mortality.

\section{ACKNOWLEDGEMENTS}

Authors sincerely thank to the Department of Obstetrics and Gynecology, Umaid Hospital, Dr. S. N. Medical College, Jodhpur, Rajasthan for providing support and assistance.

Funding: No funding sources

Conflict of interest: None declared

Ethical approval: The study was approved by the Institutional Ethics Committee

\section{REFERENCES}

1. Pinas-Carrillo A, Chandraharan E. Management of morbidly adherent placenta. Obstet Gynaecol Reproduc Med. 2016;26(10):283-90.

2. Committee on Obstetric Practice. Committee Opinion no.529. Placenta accreta. Obstet Gynecol 2012;120:207-11.

3. Miller DA, Chollet JA, Goodwin TM. Clinical risk factors for placenta previa-placenta accreta. Am J Obstet Gynecol. 1997;177:210-4.
4. Jwarah E, Wilkin DJ. Conservative management of placenta accreta. J Obstet Gynaecol. 2006;26:378-9.

5. Leerentveld RA, Gilberts ECAM, Arnold KJCW, Wladimiroff JW. Accuracy and safety of transvaginal sonographic placental localization. Obstet Gynecol. 1990;76:759-62.

6. Timor-Tritsch IE, Yunis RA. Confirming the safety of transvaginal sonography in patients suspected of placenta previa. Obstet Gynecol. 1993;81:742-4.

7. Wong HS, Ying KC, Zuccollo J, Tait J, Pringle KC. Evaluation of sonographic diagnostic criteria for placenta accrete. J Clini Ultrasound. 2008;36(9):5519.

8. Shawky M, AbouBieh E, Masood A. Gray scale and Doppler ultrasound in placenta accreta: Optimization of ultrasound signs. Egyptian J Radiol Nuclear Medic. 2016;47(3):1111-5.

9. Hamisa M, Mashaly E, Fathy S, Tawfeek A. Role of Doppler US and MRI in diagnosis of placenta accrete. Alexandria J Medic. 2015;51:225-30.

10. Royal College of Obstetricians and Gynaecologists Guideline; 2011:27.

11. Solheim KN, Little SE, Esakoff TF, Cheng YW, Sparks TN, Caughey AB. How will increases in cesarean rates affect the incidence of placenta previa, placenta accreta, and maternal death in future years? AJOG. 2008;199(6):S88.

12. Robinson BK, Grobman WA. Effectiveness of timing strategies for delivery of individuals with placenta previa and accreta. Obstet Gynecol. 2010;116:835-42.

13. Seago DP, Roberts WE, Johnson VK, Martin RW, Morrison JC, Martin JN Jr. Planned cesarean hysterectomy; a preferred alternative to separate operations. Am J Obst Gynecol. 2004;104;537-40.

14. Robinson BK, Grobman WA. Effectiveness of timing strategies for delivery of individuals with placenta previa and accreta. Obstet Gynecol. 2010;116:835-42.

15. Eller AG, Bennett MA, Sharshiner M, Masheter C, Soisson AP, Dodson M. Maternal morbidity in cases of placenta accreta managed by a multidisciplinary care team compared with standard obstetric care. Obstet Gynecol. 2011;117(2):331-7.

16. Hughes EC. Obstetric-Gynecologic terminology with section on Neonatology and glossary on congenital anomalies. In: American College of Obstetricians and Gynecologists. FA Davis Co. Philadelphia (PA);1972.

Cite this article as: Desai R, Jodh BS, Garg R. Morbidly adherent placenta and it's maternal and fetal outcome. Int J Reprod Contracept Obstet Gynecol 2017;6:1890-3. 